\title{
Varieties of intensification
}

\section{Remarks on Beltrama and Bochnak 'Intensification without degrees cross-linguistically'}

\author{
Lisa Bylinina ${ }^{1} \cdot$ Yasutada Sudo $^{2}$
}

Received: 14 May 2014 / Accepted: 30 September 2014 / Published online: 13 May 2015

(C) The Author(s) 2015. This article is published with open access at Springerlink.com

\begin{abstract}
This paper is a commentary on Beltrama and Bochnak (2015), who propose a uniform semantics for different uses of cross-categorial intensifiers -issimo in Italian and šému in Washo as universal quantifiers over contexts. Two concerns of their uniform semantics are raised, (i) unexpected restrictions on intensification, and (ii) non-truth-conditional intensification. It is argued that a uniform semantics like Beltrama and Bochnak's is unachievable, and suggested that the multitude of uses commonly observed with intensifiers should be captured in terms of semantic similarity, rather than semantic identity.
\end{abstract}

Keywords Intensification · Modification · Granularity

\section{Introduction}

Beltrama and Bochnak (2015, this volume), henceforth B\&B, observe that Italian -issimo and Washo šému serve as intensifiers in a number of distinct domains. They discuss the following six uses of these two cross-categorial intensifiers. For reasons of space, we will focus on -issimo in the present commentary. ${ }^{1}$

\footnotetext{
${ }^{1}$ B\&B do not present compelling evidence that šému has the second use (precisification effects with nouns) and the fifth use (exclamative effects with nouns). They adduce their (16) as an example of the former but as they themselves remark (in footnote 9 and in Sect. 2.5), it could well be an instance of the confirmative use. Also, they claim that -issimo has morphosyntactic constraints that prevent it from combining with certain expressions (see footnotes 2 and 3 ).
}

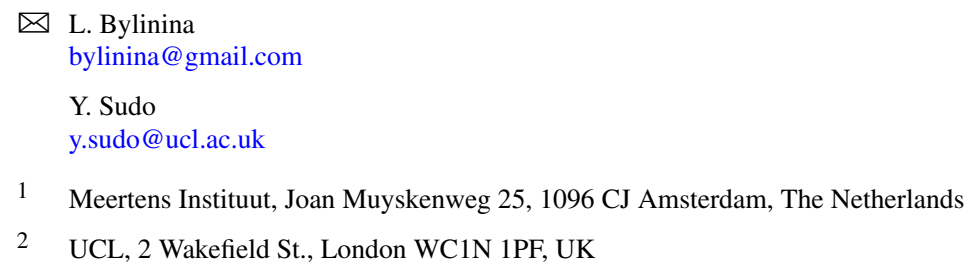


1. Degree intensification

(1) La torre è alt-issima. the tower is tall-ISSIMO

'The tower is very/extremely tall.'

(B\&B's (9a))

2. Precisification effects with non-gradable predicates

(2) Fumare dal benzinaio è proibit-issimo.

smoking at.a gas.station is forbidden-ISSIMO

'Smoking at a gas station is absolutely/strictly forbidden.'

(B\&B’s (14a))

3. Prototypicality effects with nouns ${ }^{2}$

(3) Michael Jordan è un campion-issimo.

Michael Jordan is a champion-ISSIMO

'Michael Jordan is a big/real champion/the champion of champions.'

(B\&B's (23))

4. Confirmative uses

(4) A: 7 è un numero primo?

7 is a number prime

'Is 7 a prime number?'

B: Prim-issimo! / ??Molto Primo!

prime-ISSIMO very prime

'Absolutely prime!'

(B\&B's (31a))

(5) A: 7 non è un numero primo.

7 not is a number prime

'7 is not a prime number.'

B: Ma no! È prim-issimo! / ??È molto primo!

but no is prime-ISSIMO is very prime

'No! It's absolutely prime!'

(B\&B's (31b))

5. Exclamative effects with nouns

(6) Lampugh-issima in Alto Adriatico

dorado-ISSIMO in northern Adriatic.Sea

' $\{$ Outstanding / Huge / Spectacular $\}$ exemplar of dorado-fish caught in northern Adriatic Sea'

(B\&B's (24))

6. Intensification with quantifiers and ordinals ${ }^{3}$

\footnotetext{
${ }^{2} \mathrm{~B} \& \mathrm{~B}$ note that -issimo as a nominal suffix is a very recent use and less productive, and its acceptability varies considerably both across speakers and across nouns. Our informant has remarked that campionissimo in (3) is acceptable but is more or less a fixed expression, and for him, (6) is unacceptable, even with the context that $\mathrm{B} \& \mathrm{~B}$ present.

${ }^{3} \mathrm{~B} \& \mathrm{~B}$ remark that modification of numerals is possible with šému but not with -issimo, and claim that the latter has a morphosyntactic restriction. Incidentally, they mention that Washo lacks items like nessuno
} 
a. Non c'è nessun-issima possibilià di vincere. not there.is any-ISSIMO chance of winning

'There is no chance at all to win the game.'

b. Per la prim-issima volta, ho vinto una scommessa.

fo the first-ISSIMO time I.have won a bet

'For the very first time I won a bit.'

c. Voglio chiederti l' ultim-issima cosa.

I.want to.ask.you the last-ISSIMO thing

'I want to ask you the very last thing, then you are off the hook.'

(Adapted from B\&B's (26)-(27))

In order to achieve a uniform semantic account of these different uses, B\&B analyze the two intensifiers as universal quantifiers over contextual parameters affecting the interpretation of the context-sensitive item they modify.

In this commentary, we raise empirical concerns of their uniform semantic treatment of the different uses. Firstly, we observe that not all context-sensitive items can be modified by -issimo in the way they predict. For example, unlike the negative quantificational determiner nessuno 'any', indefinite determiners, e.g. un, qualcun, alcun, cannot combine with -issimo (although they have confirmative readings in appropriate contexts).

a. *Un-issimo studente è venuto alla festa. a-ISSIMO student is come to.the party

b. *Qualcun-issimo studente è venuto alla festa. some-ISSIMO student is come to.the party

c. *Alcun-issimo studente è venuto alla festa. some-ISSIMO student is come to.the party

The semantics that $\mathrm{B} \& \mathrm{~B}$ suggest for -issimo, however, predicts (8) to be possible with truth-conditions involving universal quantification. ${ }^{4}$

Secondly, contrary to the predictions of their analysis, not all types of intensification are truth-conditional in nature. Interestingly, they seem to be aware of this, as suggested by their repeated remark that the two intensifiers in question have no truthconditional consequences when they modify non-gradable predicates like forbidden, which they illustrate with (9).

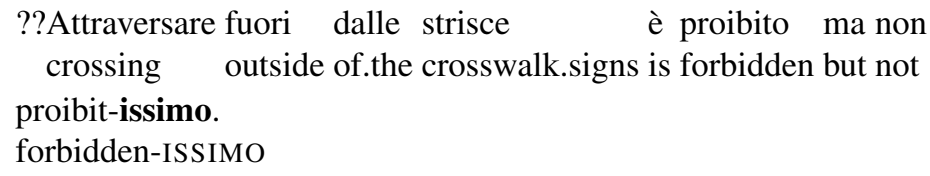

\footnotetext{
'nobody', primo 'first', and ultimo 'last' altogether, and thus whether šému can modify them cannot be tested.

${ }^{4}$ As the guest editors pointed out to us, B\&B suggest the possibility that nessuno 'any' undergoes typeshifting when modified by -issimo, and with this assumption, they could stipulate that type-shifting cannot apply to the determines in (8). However, this solution would be ad hoc. Rather, as we will suggest in Sect. 3 , the relevant restrictions seem to be rooted in the meanings of the determiners.
} 
Intended: 'Crossing outside the crosswalk is forbidden, but not absolutely forbidden.'

(B\&B's (15))

The unacceptability of this sequence indicates that the meaning of -issimo cannot take scope under negation. Despite this observation, however, B\&B pursue a uniform semantics where intensification by -issimo/šému is always truth-conditional, which wrongly assigns a coherent meaning to sentences like (9).

We take these observations as showing that a uniform semantics like B\&B's is not achievable, and that there are distinct kinds of intensification at the semantic level. However, we agree with B\&B's intuition that it is not a mere morphological accident that different sorts of intensification are very often expressed by the same morphological item, and this should be given a semantic account. Instead of giving identical semantics to different types of intensification, we suggest that they should be given similar meanings, which are sometimes lumped together in morphology.

We begin our discussion by first formally clarifying B\&B's proposal in Sect. 2. In Sect. 3, we point out unexpected semantic restrictions on -issimo illustrated by (8), and in Sect. 4, we turn to the problem of non-truth-conditional intensification in sentences like (9). These two problems lead us to renounce a uniform semantics. In Sect. 5, we suggest instead that the cross-linguistic tendency for different types of intensification to be expressed by the same lexical item should be explained in terms of semantic similarity, rather than semantic identity.

\section{B\&B's uniform semantics}

We first review B\&B's semantics of -issimo (and šému). ${ }^{5}$ We will reformulate their analysis with more formal precision here, which will clarify the predictions of their analysis. $^{6}$

According to $\mathrm{B} \& \mathrm{~B}$, -issimo intensifies a context-sensitive one-place predicate $P$ by universally quantifying over possible contexts in the following manner.

$$
\llbracket \text {-issimo } P \rrbracket_{\mathcal{M}}^{c}=\lambda x_{e} . \forall c^{\prime} \in \operatorname{AltCtx}_{c}(P)\left[\llbracket P \rrbracket_{\mathcal{M}}^{c^{\prime}}(x)=1\right]
$$

The domain of quantification is restricted to the set $\operatorname{AltCtx}_{c}(P)$, which is meant to be the set of contexts $c^{\prime}$ such that $c^{\prime}$ and $c$ are identical except possibly in the parameters relevant for the interpretation of $P{ }^{7}$ The predicate $P$ modified by -issimo is contextsensitive, i.e. its meaning depends on possible contexts (represented by $c, c^{\prime}$, etc.) in a

\footnotetext{
${ }^{5}$ They also discuss the expressive component of -issimo. As we have nothing to add to this aspect of their proposal, we will ignore it in the present commentary, concentrating on the at-issue dimension. We also have nothing to say about its combinatoric restrictions mentioned in footnote 4.

${ }^{6}$ Intensionality and variable assignment play no crucial role, we will assume an extensional system without assignments.

${ }^{7}$ More specifically, $\operatorname{AltCtx}_{c}(P)=\left\{c^{\prime} \mid \llbracket P \rrbracket_{\mathcal{M}}^{c} \neq \llbracket P \rrbracket_{\mathcal{M}}^{c^{\prime}}\right\} \cup\{c\}$. In B\&B's original exposition the parameter $P$ is not overtly expressed but strictly speaking, it is needed to properly restrict the domain of quantification. Also, we present (10) syncategorematically, as shifting the context index necessitates a non-standard compositional rule (cf. von Stechow and Zimmermann's 2005 Monstrous Functional Application).
} 
non-trivial way. Under B\&B's view, there are several distinct ways of being contextsensitive, all of which can be intensified by the above meaning of -issimo. Let us look at each case in turn.

One type of context-sensitivity is manifested by positive forms of gradable predicates. Following the standard degree semantics (Cresswell 1976; von Stechow 1984; Kennedy 1999), B\&B assume that they are syntactically decomposable into the POS operator (in languages like Italian and English).

$$
\llbracket \mathrm{POS} \text { tall } \rrbracket_{\mathcal{M}}^{c}=\lambda x_{e} . \exists d[\langle x, d\rangle \in I(\text { tall }) \wedge d=\operatorname{Std}(c, \text { tall })]
$$

$I$ here is the interpretation function, which is part of the model $\mathcal{M}$, and assigns to a gradable predicate like tall a set of pairs consisting of an individual $x$ and a degree $d$ such that $x$ is at least $d$-tall. Crucially, POS introduces the standard function $\operatorname{Std}()$, which returns the standard degree for a gradable predicate and a context. When combined with -issimo, (11) yields the following meaning:

$$
\lambda x_{e} . \forall c^{\prime} \in \operatorname{AltCtx}_{c}(\operatorname{POS} \text { tall }) \exists d\left[\langle x, d\rangle \in I(\text { tall }) \wedge d=\operatorname{Std}\left(c^{\prime}, \text { tall }\right)\right]
$$

This predicate is true of an individual $x$ iff $x$ 's height reaches the standard degree in every context that affects the standard of tallness, not just in $c$. This implies that $x$ is extremely tall.

A second type of context-sensitivity is exhibited by non-gradable predicates like forbidden, for which intensification by -issimo results in precisification effects, as shown in (2). In order to account for this, B\&B make recourse to pragmatic halos proposed by Lasersohn (1999). The idea is that for a one-place predicate $P$ like forbidden that is subject to pragmatic imprecision, its denotation in context $c$ may be a superset of its strictest interpretation $I(P)$ and include some additional individuals. We denote those additional individuals for $P$ in $c$ by $\operatorname{Halo}(c, P) .^{8}$ More concretely, we represent the meaning of forbidden as follows.

$$
\left.\llbracket \text { forbidden } \rrbracket_{\mathcal{M}}^{c}=\left[\lambda x_{e}, x \in(I \text { (forbidden }) \cup \operatorname{Halo}(c \text {, forbidden })\right)\right]
$$

When -issimo modifies forbidden, it gives rise to the following meaning.

$$
\left.\left.\lambda x_{e} . \forall c^{\prime} \in \operatorname{AltCtx}_{c} \text { (forbidden }\right)\left[x \in(I \text { (forbidden }) \cup \operatorname{Halo}\left(c^{\prime}, \text { forbidden }\right)\right)\right]
$$

Given that the set $\operatorname{AlCtx}_{c}$ (forbidden) includes very strict contexts where the halo for forbidden is empty or at least very small in size, in order for (14) to be true of $x$, $x$ ought to be in $I$ (forbidden). Consequently one gets an interpretive effect similar to that of strictly speaking.

The prototypicality effects observed with nouns exemplified by (3) are accounted for in a similar manner. B\&B assume that the extensions of relevant nouns are sensitive to possible contexts, just like predicates like forbidden, but unlike forbidden, the denotation of a noun $P$ in context $c$ may be a subset, rather than a superset, of $I(P)$. We formalize this idea by using the function Margin() that maps every pair

\footnotetext{
${ }^{8}$ For expository purposes, we define $\operatorname{Halo}(c, P)$ to be disjoint from $I(P)$, while for Lasersohn (1999) it is always the case that $P \subseteq \operatorname{Halo}(c, P)$. This modification is harmless, as Lasersohn's notion is simply Halo $(c, P) \cup I(P)$. We also ignore the ordering relation among the members of Halo $(c, P)$, as it plays no role in the present phenomenon.
} 
of context $c$ and predicate $P$ to the set of marginal members of $P$ in context $c$ (so $\operatorname{Margin}(c$, champion $\subseteq \subseteq$ (champion) is always the case).

$$
\left.\llbracket \text { champion } \rrbracket_{\mathcal{M}}^{c}=\left[\lambda x_{e}, x \in(I \text { (champion })-\operatorname{Margin}(c, \text { champion })\right)\right]
$$

When modified by -issimo, the predicate will be restricted to those members of $I$ (champion) that are not in the margin in any context, i.e. they are the prototypical members.

B\&B's semantics furthermore accounts for intensification with quantifiers and ordinals exemplified by (7). Crucially, the relevant items are assumed to be associated with contextually restricted domains of quantification. ${ }^{9}$ As we will detail their analysis of quantifiers in Sect. 3, let us focus on ordinals here. In order to avoid unnecessary complication (especially to keep our semantics extensional), we will not go into the detailed semantics of ordinals (see Bhatt 2006; Sharvit 2010; Bhatt and Pancheva 2012; Ivlieva and Podobryaev 2012; Bylinina et al. 2014), but the idea is roughly the following: La prima volta 'the first time' refers to the first time among the contextually determined domain consisting of different times. Since -issimo strengthens the predicate by universally quantifying over such contexts, la prim-issima volta will be the first time among all possible domains, i.e. the very first time. ${ }^{10}$

$\mathrm{B} \& \mathrm{~B}$ argue that the other two uses, the confirmative use and the exclamative use, involve coercion of a context-invariant predicate into a context-sensitive one. For (4) and (5), B\&B suggest in the following passage (Sect. 4.2.3) that prime is normally context-invariant, but uncertainty in certain discourse configurations may trigger the relevant coercion into a context-sensitive predicate.

When [primo] is used out of the blue, its interpretation does not contain any contextual parameter, and universal quantification yields a trivial result: whatever the value for $c, 7$ will always be a prime number, rendering the suffix redundant. However, the uncertainty induced by a question or a rebuttal takes away this clear-cut boundary between the extensions of $P$ and $\neg P$. Note that

\footnotetext{
${ }^{9} \mathrm{~B} \& \mathrm{~B}$ only present a rough idea for intensification with quantifiers and numerals, but, as they suggest, since it is natural to assume that quantifiers like nessuno have contextual domain restrictions (cf. Chierchia 2006) and that at least round numerals tolerate non-strict interpretations, B\&B's account can in principle be extended to cover these uses.

${ }^{10}$ Incidentally we observe that -issimo cannot modify all ordinals, a fact that B\&B do not mention. In fact, only primo 'first' and ultimo 'last' are compatible with -issimo, and other ordinals generally resist -issimo (although they allow confirmative uses in appropriate contexts), as illustrated by (i).
}

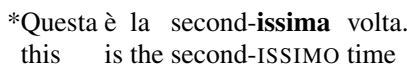

This might seem puzzling for B\&B's analysis given that all ordinals are equally context-sensitive. However, first and last vs. other ordinals differ in terms of entailment properties with respect to their contextual domain. That is, first is downward entailing with respect to the domain in the sense that if $x$ is ranked first in $D$, then $x$ necessarily remains first in any subset $D^{\prime}$ of $D$ (provided $x \in D^{\prime}$ ), including $\{x\}$. The same holds for last. On the other hand, second is non-monotonic in the sense that for any individual $x$ that is ranked second in $D$, it is possible to find a subset of $D$ such that $x$ fails to be second in it, e.g. $\{x\}$. B\&B could capitalize on this in order to account for the restriction on -issimo. That is, sentences like (i) can never be true if -issimo quantifies over contexts where the domain is a set like $\{x\}$. In fact, according to $\mathrm{B} \& \mathrm{~B}, \mathrm{AltCtx}_{C}$ (second) necessarily includes such contexts. 
the boundary between prime and not prime does not become blurry per se. Rather, what creates room for variability is the fact that the speakers in the context cannot come to an agreement as to where such boundary lies, creating the pragmatic conditions to specify that a certain individual (number 7 here) is indisputably a member of the extension of the property.

Here is an attempt to formalize this idea. As they suggest in this quote, we assume that the default semantics of prime is context-invariant. That is, its denotation does not refer to $c$, as in (16a). In certain discourse configurations, however, it can be coerced into a context-variant version. Although it is not entirely clear to us what B\&B actually envisage, we will postulate a context-sensitive function Controversial() that takes a possible context $c$ and a one-place predicate $P$, and picks out a subset of members whose membership in $P$ is controversial in $c$. The context-sensitive version of prime looks like (16b).

$$
\begin{array}{ll}
\text { a. } & \llbracket \text { prime } \rrbracket_{\mathcal{M}}^{c}=\left[\lambda x_{e} . x \in I(\text { prime })\right] \\
\text { b. } & \llbracket \text { prime } \rrbracket_{\mathcal{M}}^{c} \rightsquigarrow\left[\lambda x_{e} . x \in(I(\text { prime })-\operatorname{Controversial}(c, \text { prime }))\right]
\end{array}
$$

One attractive feature of this analysis, as $\mathrm{B} \& \mathrm{~B}$ point out, is that on the assumption that the relevant coercion is a costly operation, it captures the observation that examples like (4) and (5) generally require contextual support and are not perfectly acceptable out of the blue. Furthermore, this analysis nicely explains B's confrontational attitudes in (4) and (5). In these examples, B's utterances mean that in all contexts 7 is uncontroversially a prime number, which contradicts A's assumption. Specifically, in (4) A's question suggests that A thinks 7 might not be a prime, and in (5), A asserts that it is not. B's use of -issimo basically rejects A's discourse moves by asserting that the proposition of 7 being prime is uncontroversial.

$\mathrm{B} \& \mathrm{~B}$ observe that the exclamative effects manifested by nominal uses of -issimo in sentences like (6) also require strong contextual support, but suggest in the following passage (Sect. 4.2.3) that they do so for a different reason from the confirmative use.

In (6), however, what triggers [context variability] is not uncertainty, but rather the speaker himself, who introduces a new, more restricted partitioning of the extension on the fly. While under normal circumstances the extension of lampuga ['dorado fish'] is fixed (presumably, by a set of clearcut biological criteria), in the new one it only includes a subset of the original extension. Crucially, the sense in which the new partitioning is different from the original one must be retrievable from the context. In the case of (6), the picture shows a rather massive exemplar of the fish, which leads to the inference that only dorado fish over a certain size can be considered members of the new extension.

To formalize this idea, one might be tempted to use a context-sensitive function like Banal(), which maps every context-predicate pair to a subset of the extension of the predicate containing the non-noteworthy individuals in the context, as in (17b), but this results in wrong predictions.

$$
\begin{array}{ll}
\text { a. } & \llbracket \text { dorado } \rrbracket_{\mathcal{M}}^{c}=\left[\lambda x_{e}, x \in I(\text { dorado })\right] \\
\text { b. } & \llbracket \text { dorado } \rrbracket_{\mathcal{M}}^{c} \rightsquigarrow\left[\lambda x_{e} . x \in(I(\text { dorado })-\operatorname{Banal}(c, \text { dorado }))\right]
\end{array}
$$


The reason why (17b) is inappropriate is that according to the above quote, the relevant scale of noteworthiness may vary across contexts and when combined with -issimo, (17b) will be true of only those individuals that are noteworthy according to all criteria, not just their size. Thus, we need a more specific function, e.g. Banal.Size(), which maps every context-predicate pair to a subset of the extension of the predicate consisting of individuals whose size is not noteworthy in the context.

$$
\llbracket \text { dorado } \rrbracket_{\mathcal{M}}^{c} \rightsquigarrow\left[\lambda x_{e} . x \in(I(\text { dorado })-\operatorname{Banal.Size}(c, \text { dorado }))\right]
$$

When modified by -issimo, (18) will be true only of dorado fish whose sizes are noteworthy in every context, which captures the intended reading. By assumption, other functions like Banal.Taste() and Banal.Beauty() should be available in the right contexts, although relevant data are missing. ${ }^{11}$

In this section we reviewed B\&B's uniform semantics for different uses of -issimo in some detail. Although it has appealing features, we will raise empirical concerns that cast doubt on it. We take these observations to suggest that at the semantic level there are distinct types of intensification.

\section{Unexpected restrictions on intensification of quantifiers}

B\&B's example reproduced in (7a) above shows that nessuno 'any' can be intensified with -issimo. B\&B analyze this example as follows. It is commonly assumed that quantificational determiners come with an implicit contextually determined domain restriction (e.g. Westerståhl 1984; Chierchia 2006). B\&B suggest that -issimo operates on quantificational domains by manipulating contexts. More specifically, (7a) can be analyzed as follows. ${ }^{12}$

$$
\begin{aligned}
& \forall c^{\prime} \in \operatorname{AltCtx}_{c} \text { (nessun) } \\
& \neg \exists x\left[x \in \mathrm{QDom}\left(c^{\prime} \text {, nessun }\right) \wedge x \in I \text { (chance.of.winning) }\right]
\end{aligned}
$$

Here, QDom() maps each context-determiner pair to the domain of quantification of the determiner in the context. Crucially, this is a context-sensitive function that -issimo can operate on, and -issimo delivers a stronger meaning in this case. Notice that it is essential that the universal quantifier encoded in the meaning of -issimo takes scope over the negation. Although $\mathrm{B} \& \mathrm{~B}$ are vague about how this is achieved, let us simply accept it.

Although B\&B account works for nessuno, however, we point out that it overgenerates for certain other determiners. As we saw already in (8), indefinites generally

\footnotetext{
${ }^{11}$ The exclamative use of -issimo bears certain similarities with constructions like $w h$-nominal exclamative constructions (e.g. What peppers he ate!). They could be given a related analysis in terms of the same contextually determined implicit functions. However, it is currently controversial whether or not they involve degrees, and both degree and non-degree analyses have been offered (Zanuttini and Portner 2003; Rett 2011; Nouwen and Chernilovskaya 2013).

${ }^{12} \mathrm{As} \mathrm{B} \& \mathrm{~B}$ correct point out, for compositional reasons, -issimo in this sentence has to type-raise, as a determiner is of type $\langle e t,\langle e t, t\rangle\rangle$, rather than $\langle e, t\rangle$. However, as B\&B's assumptions about nessuno and negation are unclear in their exposition, we only discuss the sentence level meaning here. The problem we point out here is independent from this point.
} 
resist modification by -issimo (however, these sentences seem to allow confirmative uses in appropriate contexts). This is unexpected under B\&B's analysis. That is, just like nessuno, indefinite determiners also have contextually determined domains of quantification. In order to see this clearly, consider the sentence in (20).

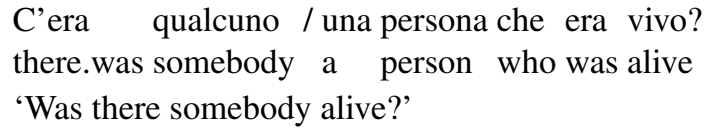

Under the most natural interpretation of the sentence, it is pragmatically anomalous to answer this question by saying, 'Yes, me', which means that the domain of quantification is implicitly restricted to a set that does not contain the addressee. Thus, indefinites do come with contextually determined domains of quantification. Then, B\&B's analysis predicts that the sentence in (8) should mean something close to universal quantification, due to -issimo, which demands the existential statement to be true in all contexts. However, such an interpretation is unobserved.

This problem casts doubt on B\&B's analysis. Although B\&B impose morphosyntactic restrictions on the distribution of -issimo, it is unlikely that the restriction that -issimo cannot modify indefinite determiners is morphosyntactic in nature, because it can combine with other determiners like nessuno. Rather, the relevant restriction seems to be semantic in nature. However, in order to treat different sorts of intensification uniformly, B\&B make the meaning of -issimo oblivious to the nature of meaning it is modifying. This makes it impossible to formulate the relevant semantic restriction.

\section{Non-truth-conditional intensification}

Let us now turn to the second problem of non-truth-conditional intensification. B\&B observe that in the degree intensification use, the unmodified form is compatible with the negation of the modified form, as shown by (21).

La torre è alta ma non alt-issima.
the tower is tall but not tall-ISSIMO

'The tower is tall but not extremely tall.'

(B\&B's (11))

B\&B's analysis captures this observation as follows. With our reformulation of their analysis, its meaning with respect to context $c$ looks like (22). To simplify, we assume la torre to denote a specific tower $t$.

$$
\begin{aligned}
& \exists d[\langle t, d\rangle \in I(\text { tall }) \wedge d=\operatorname{Std}(c, \text { tall })] \wedge \\
& \neg \forall c^{\prime} \in \operatorname{AltCtx}_{c}(\text { POS tall }) \exists d^{\prime}\left[\left\langle t, d^{\prime}\right\rangle \in I(\text { tall }) \wedge d^{\prime}=\operatorname{Std}\left(c^{\prime}, \text { tall }\right)\right]
\end{aligned}
$$

The first clause says that $t$ is at least as tall as the standard height in the current context $c$, while the second clause says that in some possible context $c^{\prime}$ that differs from $c$ at most in the evaluation of POS tall, $t$ is not as tall as the standard height in $c^{\prime}$. This is a contingent statement and captures the reading of (21).

However, a problem arises with (9), which they observe is contradictory, unlike (21). 
(9)
??Attraversare fuori dalle strisce
è proibito ma non
crossing
outside of.the crosswalk.signs is forbidden but not proibit-issimo.
forbidden-ISSIMO

Intended: 'Crossing outside the crosswalk is forbidden, but not absolutely forbidden.'

(B\&B's (15))

$\mathrm{B} \& \mathrm{~B}$ remark on this example as follows (Sect. 2.2): "the suffix, contrary to what we observed with gradable adjectives, appears to have no effect on the truth conditions of the predicate. As a consequence, it cannot be targeted by negation while the unmodified form still holds." However, their semantic analysis is inherently truth-conditional, and they in fact predict (9) to have a coherent interpretation. More concretely, in our reformulation of their account, the meaning of (9) with respect $c$ looks as follows. For the sake of simplicity, we treat the subject as denoting an individual $\dagger$.

$$
\begin{aligned}
& \dagger \in(I(\text { forbidden }) \cup \operatorname{Halo}(c, \text { forbidden }) \wedge \\
& \neg \forall c^{\prime} \in \operatorname{AltCtx}_{c}(\text { forbidden })\left[\dagger \in\left(I(\text { forbidden }) \cup \operatorname{Halo}\left(c^{\prime}, \text { forbidden }\right)\right)\right]
\end{aligned}
$$

This is not contradictory, and comes out as true, if $\dagger$ belongs to $\operatorname{Halo}(c$, forbidden) but not in $\mathrm{Halo}\left(c^{\prime}\right.$, forbidden) for some $c^{\prime} \in \operatorname{AltCtx}_{c}$ (forbidden). Thus, (9) is predicted to mean that strictly speaking crossing outside the crosswalk is not forbidden but loosely speaking it is. Essentially, this problem stems from the fact that in the degree intensification use, but not in the precisification use, -issimo needs to be able to take scope under negation, but under B\&B's uniform semantics, it is not clear how this difference can be captured.

We furthermore observe that the other uses of -issimo also resist taking scope under negation. $^{13}$

\section{Prototypicality effects with nouns}

\#Michael Jordan è un campion ma non un campion-issimo.

Michael Jordan is a champion but not a champion-ISSIMO

Intended: 'Michael Jordan is a champion but is not a typical champion.'

\section{Intensification with ordinals}

\#Questa è la prim-issima volta ma non la prim-issima volta.

this is the first-ISSIMO time but not the first-ISSIMO last time Intended: 'This is the first time but not the very first time.'

Confirmative use ${ }^{14}$
A: È il Circuit Value Problem NP-dificile?
is the Circuit Value Problem NP-hard
'Is the Circuit Value Problem NP-hard?'

\footnotetext{
${ }^{13}$ As our informant does not accept examples of exclamative effects with nouns, which B\&B acknowledge as highly marked for some speakers, they are not tested here.

${ }^{14}$ The Circuit Value Problem is known to be P-complete. Whether it is also NP-hard depends on whether $\mathrm{P}=\mathrm{NP}$, which is controversial.
} 
B: \#Non è NP-dificil-issimo.

not is NP-hard-ISSIMO

Intended: 'It is not uncontroversially NP-hard.'

B\&B's uniform semantics wrongly predicts these examples to have coherent interpretations.

Moreover, a related problem arises with quantifiers with explicit domains. Recall from Sect. 3 that according to B\&B's account, intensification of quantificational determiners has to do with contextually determined domains of quantification. However, we observe that intensification is possible with a quantifier whose domain of quantification is linguistically specified and hence is not contextually determined. To see the problem more clearly, consider the following example involving a universal quantifier.

Tutt-issimi i dieci studenti sono venuti alla festa. all-ISSIMO the ten students be.3pl come to.the party

'All the ten students came to the party.'

While (27) is perfectly grammatical and acceptable in neutral contexts, it is clear that the intensification is not about the domain of quantification. That is, the sentence is truth-conditionally identical to the version of the sentence without -issimo, i.e. (28).

Tutti i dieci studenti sono venuti alla festa.

all the ten students be.3pl come to.the party

'All the ten students came to the party.'

Both of these sentences are true just in case all of the ten students came to the party. Still, intuitively speaking, (27) with -issimo has an intensified meaning. This suggests that the intensification achieved by -issimo here is non-truth-conditional in nature. B\&B's uniform semantics is incapable of accounting for such a meaning, and predicts that it simply has no semantic contribution in (27).

\section{Varieties of intensification}

The problems discussed in the previous two sections lead us to conclude that the different uses of -issimo cannot be accounted for with a single meaning. In particular, they have different truth-conditional status: while degree intensification has truthconditional effects, other types of intensification are non-truth-conditional in nature.

Two questions immediately arise. How many semantically distinct types of intensification are there? And why is it that -issimo (and šému) expresses more than one kind of intensificational meaning? While it is far beyond the scope of the present commentary to give a comprehensive answer to the first question, we hope to give a glimpse of the empirical landscape by putting some more data onto the table. As we will see, the emerging picture is quite complex. A major stumbling block is the fact that many intensifiers across languages seem to have multiple uses, and different items encode different (but sometimes partially overlapping) sets of intensification 
meanings, which makes it hard to extrapolate from a small set of items what constitutes a semantic primitive. The lack of a clear empirical picture and a consensus on the semantics of different kinds of intensification, furthermore, renders our answer to the second question rudimentary as well. However, we suggest that there should be semantic similarities among the different kinds of intensification that are reflected in morphology.

We will illustrate the difficulty of identifying semantic primitives for intensification with some specific items. First, let us consider English very. The most widely discussed use of very is degree intensification as in sentences like He is very tall. Also, it is often recognized, explicitly or implicitly, that very cannot perform the other types of intensification that B\&B discuss. For instance, it does not have precisification, confirmative and typicality uses.

??Smoking at a gas station is very forbidden.

A: Is 7 a prime number?

$\mathrm{B}$ : *Yes, it is very prime!

B\&B do discuss this type of intensifiers (sometimes called standard-boosters), and following the standard degree semantics, suggest an analysis as degree operators. Specifically, according to one version of this idea, very is an operator that takes a gradable predicate (of type $\langle d$, et $\rangle$ ) and introduces a contextually determined high standard for it.

However, it is often overlooked that very has other uses that do not seem to be amenable to the analysis as a standard-booster. First, very can modify certain ordinals (namely, first and last; see footnote 10 for relevant discussion), and other expressions that denote beginnings and ends (beginning, end, final, etc.)

a. For the very first time I won a bet.

b. It was the very last sandwich.

At the very beginning/end of the novel, the author reveals the identity of the murderer.

Second, very occurs with certain superlatives, best, worst, most, and least, most notably (this use is perhaps related to the previous one).
a. I do the very best I know how, the very best I can, and I mean to keep on doing so until the end. (Abraham Lincoln)
b. This is the very worst of academia.
c. We made the very most of this opportunity.
d. This is the very least the university can do in this situation.

Third, again perhaps relatedly, very can modify next.

And the very next day, I realized that I made a huge mistake.

Fourth, very can combine directly with nouns.

a. I became the very person I hated in my youth. 
b. If you analyze it, I believe the very heart and soul of conservatism is libertarianism. (Ronald Reagan)

Intuitively speaking, these 'non-standard' uses of very still express intensification in some sense, but none of them are analyzable as standard-boosters. On the one hand, the constructions in question are incompatible with other degree modifiers, e.g. comparatives, enough, etc. On the other hand, not all standard-boosters have all of these four uses, e.g. Japanese standard-booster totemo and its Russian parallel očen' have none of them, although their functions overlap with English 'very' when modifying degree predicates. Thus, a uniform semantic analysis of different uses of very appears to be doomed. However, it is unclear how many different semantics should be assigned to very, a similar question we raised for -issimo. It is likely that standard boosting, which sits in the intersection of English very, Japanese totemo and Russian očen', is one semantic category of intensification, but given the lack of proper analyses of the other uses of very, we need to leave open exactly how these different uses are semantically related.

Let us now turn to a different intensifier, totally, which expresses a different set of intensification meanings from -issimo and very. It is well discussed that totally can function as a 'proportional modifier of maximality' that indicates that a natural end on a scale is reached. This use is restricted to adjectives that make reference to scales with upper bounds, e.g. empty, opaque and pure (Kennedy and McNally 2005; Morzycki 2010).

\section{a. totally $\{$ empty / opaque / pure $\}$ \\ b. \#totally $\{$ tall / bent / heavy $\}$}

In addition to this maximality use, totally is known to have a distinct intensification use (Kennedy and McNally 2005; McCready and Schwager 2009; Morzycki 2010; Beltrama 2014). ${ }^{15}$ For example, totally in (38a) is not functioning as a maximality operator, because there is no entailment to the effect that the end point is reached (in fact, intrigued does not have a natural maximal end point). Furthermore totally is even compatible with a non-gradable predicate, as in (38b).

a. I'm totally intrigued by bowling, and Kim is even more intrigued than I am.

(Kennedy and McNally 2005)

b. Mary totally came to the party.

These two different uses seem to be semantically distinct. Firstly, as Morzycki (2010) notices, other proportional maximality modifiers such as fully only have the first use. Secondly, we observe that the maximality use can take scope under operators like negation as in (39a), but not when it modifies a non-gradable predicate as in (39b) and has an intermediate status (indicated by '?') when it modifies a predicate without a natural endpoint as in $(39 \mathrm{~b}){ }^{16}$

\footnotetext{
${ }^{15}$ We thank the guest editors for this volume for drawing our attention to Beltrama (2014).

${ }^{16}$ We observe that totally can modify forbidden and available, and in this use it can take scope under negation, e.g. This is (not) totally forbidden/available. Depending on the semantic status of these adjectives, this observation suggests one of two things. Some authors, including B\&B, assume that they are non-
} 
(39) a. This rod is not totally straight. It is slightly bent.

b. ?I am not totally intrigued by bowling.

c. \#Mary did not totally come to the party.

These discussions show that it is fairly easy to find items that have more than one semantically distinct intensificational use, and -issimo (and šému) is hardly alone in this respect. However, as we remarked above, it is difficult to pin down how many distinct semantic primitives are involved. For -issimo, we concluded that at least degree intensification should be semantically distinguished from the other, non-truthconditional uses. There is nothing that prevents us from identifying the degree intensification of -issimo with the standard-boosting function of very, which might constitute one semantic category of intensification. However, for the other uses, it is moot whether any semantic unification is possible, calling for further empirical and theoretical investigations.

This also leaves open why such semantically versatile intensifiers are rampant. We do agree with B\&B that this should not be an accident in the lexicon, but we disagree with them that it should be explained with one general semantics. Rather, we suggest that it should be taken as indicative of semantic similarities among different uses of intensification. By way of illustration, take the two uses of totally discussed above. As explained above, these two uses cannot be semantically identical but we think it is viable (and desirable) to analyze the second use in terms of maximality as well, e.g. the maximality of confidence on the speaker's part with respect to the asserted content (cf. McCready and Schwager 2009). Although the details need to be worked out, if this analysis is on the right track, one could give a partial answer to why totally have these uses, namely, because they are similar in that they has to do with maximality. We think that it is not far-fetched to assume that the versatility of -issimo and very can be made sense of in a similar manner by non-uniform semantics with some core component, although how exactly this can be done is left open at this moment.

Acknowledgements We would like to thank the guest editors of the present volume, Berit Gehrke and Elena Castroviejo, for useful comments and suggestions on an earlier version of this commentary. We also thank Jacopo Romoli and Eric McCready for judgments, comments and discussion. All remaining errors are ours.

Open Access This article is distributed under the terms of the Creative Commons Attribution 4.0 International License (http://creativecommons.org/licenses/by/4.0/), which permits unrestricted use, distribution, and reproduction in any medium, provided you give appropriate credit to the original author(s) and the source, provide a link to the Creative Commons license, and indicate if changes were made.

gradable predicates (at least in the default use). If this assumption is correct, totally should have a third, precisification use, which is distinct from the two uses we identify. Previous studies present as support for this assumption the fact that these adjectives are incompatible with very and comparative constructions (cf. B\&B's footnote 7). However, there is a possibility that these adjectives are gradable predicates encoding both lower- and upper-bounded scales, and very and comparative constructions are somehow inconsistent with them. If this is the case, the relevant use of totally can be seen as an instance of the maximalization use. We do not have decisive evidence for either view at this moment. 


\section{References}

Beltrama, Andrea. 2014. From totally dark to totally old: the formal semantics of subjectification. Talk given at Sinn und Bedeutung 19, Georg-August-Universität Göttingen.

Beltrama, Andrea, and M. Ryan Bochnak. 2015, this volume. Intensification without degrees crosslinguistically.

Bhatt, Rajesh. 2006. Covert modality in non-finite contexts. Berlin: Mouton de Gruyter.

Bhatt, Rajesh, and Roumyana Pancheva. 2012. Two superlative puzzles. Handout for a talk presented at the General Initiatives in Syntactic Theory (GIST) Workshop on relative clauses, 22-23 March 2012, Ghent, Belgium.

Bylinina, Lisa, Natalia Ivlieva, Alexander Podobryaev, and Yasutada Sudo. 2014. A non-superlative semantics for ordinals and the syntax of comparison classes. Poster presented at North East Linguistic Society (NELS) 45, MIT.

Chierchia, Gennaro. 2006. Broaden your views: implicatures of domain widening and the "Logicality" of language. Linguistic Inquiry 37(4): 535-590.

Cresswell, Maxwell J. 1976. The semantics of degree. In Montague grammar, ed. Barbara Partee, 261292. New York: Academic Press.

Ivlieva, Natalia, and Alexander Podobryaev. 2012. Superlatives, ordinals, contextual restrictors, and times. Handout for a talk presented at the IX Workshop on Formal Linguistics, August 30-31, 2012, Universidade Federal do Rio de Janeiro, Rio de Janeiro, Brazil.

Kennedy, Christopher. 1999. Projecting the adjective: the syntax and semantics of gradability and comparison. New York: Garland Press.

Kennedy, Christopher, and Louise McNally. 2005. Scale structure, degree modification, and the semantics of gradable predicates. Language 81: 345-381.

Lasersohn, Peter. 1999. Pragmatic halos. Language 75(3): 522-551.

McCready, Eric, and Magdalena Schwager. 2009. Intensifiers. Talk given at the German Linguistics Society (DGfS) workshop "Expressives and other kinds of non-truth-conditional meaning", Universität Osnabrück.

Morzycki, Marcin. 2010. Adjectival extremeness: degree modification and contextually restricted scales. Natural Language and Linguistic Theory 30(2): 567-609.

Nouwen, Rick, and Anna Chernilovskaya. 2013, submitted. Wh-exclamatives with and without scales. Ms., Utrecht University.

Rett, Jessica. 2011. Exclamatives, degrees and speech acts. Linguistics and Philosophy 34(5): 411-442.

Sharvit, Yael. 2010. Infinitival superlatives: English vs. Modern Hebrew. Brill's Annual of Afroasiatic Languages and Linguistics 2: 213-247.

von Stechow, Arnim. 1984. Comparing semantic theories of comparison. Journal of Semantics 3(1-2): $1-77$.

von Stechow, Arnim, and Thomas Ede Zimmermann. 2005. A problem for a compositional treatment of de re attitudes. In Reference and quantification: the Partee effect, eds. Gregory N. Carlson and Francis Jeffry Pelletier, 207-228. Stanford: CSLI.

Westerståhl, Dag. 1984. Determiners and context sets. In Generalized quantifiers and natural language, eds. Johan van Benthem and Alice ter Meulen, 45-71. Dordrecht: Foris.

Zanuttini, Raffaella, and Paul Portner. 2003. Exclamative clauses: at the syntax-semantics interface. Language 79(1): 39-81. 